\title{
The Scalability of H. Igor Ansoff's Strategic Management Principles for Small and Medium Sized
} Firms

\author{
Dr. Dan Kipley \\ School of Business and Management, Azusa Pacific University \\ PO Box 7000, Azusa, California 91702-7000 \\ Tel: 1- 626-815-6000Ｅ-mail: dkipley@apu.edu \\ Dr. Alfred Lewis. \\ Department of Business, Montreat College \\ P.O Box 1267, Montreat, North Carolina 28757 \\ Tel: 1-828-669-8012 E-mail: alewis@montreat.edu
}

\begin{abstract}
The purpose of this paper is to examine the praxis of the multi-dimensional components of $\mathrm{H}$. Igor Ansoff's Strategic Management Systems and the efficacy of use of each of its components relative to the formulation and implementation of corporate level strategy in for-profit, not-for-profit, Small and Medium sized enterprises.

Based on empirically validated research and industry supported journals, substantial evidence endorse both an implicit and explicit acknowledgement of its applicability and it $^{1}$ s value as a whole or in part providing increased financial performance for firms competing in turbulent environments.
\end{abstract}

There is a notable variance within industry and academia concerning the asymmetry of costs incurred relative to the benefits achieved of the successful implementation of Ansoffian Strategy within Small and Medium sized enterprises. Although the principles and processes of scalability are still conceptually at an embryonic stage, this paper will illuminate those features of Ansoff's Strategic Management Systems and conditions for optimal use.

Finally, we will discuss Ansoff's Strategic Success Paradigm and principles for use by Small and Medium Sized Enterprises, which when implemented have proven empirically to increase the firm's probability of strategic success.

Keywords: Ansoffian Principles, SME Strategy, Environmental Turbulence, Strategic Surprise 


\section{Introduction}

In the last half century there has been a widespread agreement between academics and practitioners in the literature that business environments have become increasingly multidisciplinary and complex and that a major escalation of environmental turbulence has taken place (D’Aveni, 1994; Day and Reibstein, 1997: Eisenhardt and Brown, 1998; Normann, 2001; Galbraith, 2002).

Small and medium sized enterprises (SMEs) are no longer exempt from environmental conditions that until recently were often the drivers of strategic decisions in large organizations, and now find themselves subject to the same rapid, novel, and discontinuous changes that have become amplified due to the exponential advancements in technology and globalization.

Thus, SME managers are now subject to the real threat and/or possibility that their firm/industry will be the one that is affected by these environmental discontinuities and as such, are an agent of change to the traditional methods in which SMEs formulate and implement their strategic plans.

The environmental discontinuity is driven in part by those entrepreneurial spirited small businesses that have been a vital factor to the growth success of new and novel advancements in computers, biotechnology, and other related technology industries (Berger and Udell, 1998).

In Europe, $99.8 \%$ of all business fall into the category of SME and employ approximately $66 \%$ of all workers (Pichler, et al., 1996), with the United States reporting that the percentage of SMEs are estimated to exceed $95 \%$ of all enterprises.

Data compiled by the The European Observatory of SMEs 2002 confirms Pichler, et al., in which the Europe-19 (EEA countries and Switzerland) account for almost 20 million SMEs providing employment for 117 million people. Of the approximate 20 million SMEs, over 18 million are considered micro enterprises, employing less than 10 people.

Profitability of SMEs compared to Large-Sized Enterprises (LSEs) varies per region with LSE's in Belgium and Greece more profitable than LSEs; Ireland, Italy, Luxembourg, Iceland, and Liechtenstein approximately the same profitability as LSEs; and 12 of the Europe-19 with significantly less profitability than LSEs.

The following table (Figure 1) illustrates this data as is estimated by Enterprise Incentive Management (EIM) Small Business Research and Consultancy of the numbers of SMEs per country. Data indicates that although SMEs numbers have increased significantly during the last 10 years (Figure 2), SMEs are competing in increasingly turbulent business environment that is directly affecting the attrition rate. This new competitive climate in which SMEs have to exist correlate to Ansoff's description of environmental turbulence Levels 4-5, specifically; increases in globalization as well as technological advancements, labor productivity, and increased level of competition within markets increases the turbulence level and has a direct causal effect on the ability of SMEs to not only compete successfully, but also survive (The 
European Observatory for SMEs).

\begin{tabular}{|cc|cc|}
\hline \multicolumn{4}{|c|}{ SME Enterprises 1998 } \\
Enterprises (1000) \\
\hline Austria & 285 & Portugal & 690 \\
\hline Belgium & 530 & Spain & 2510 \\
\hline Denmark & 150 & Sweden & 385 \\
\hline Finland & 210 & $\begin{array}{c}\text { United } \\
\text { Kingdom }\end{array}$ & 3660 \\
\hline France & 2325 & $\begin{array}{c}\text { Total EU } \\
19370\end{array}$ \\
\hline Germany & 3515 & Iceland & 30 \\
\hline Greece & 620 & $\begin{array}{c}\text { Liechtenstein } \\
3\end{array}$ \\
\hline Ireland & 85 & Norway & 205 \\
\hline Italy & 3940 & Switzerland & 240 \\
\hline Luxembourg & 15 & $\begin{array}{c}\text { Total } \\
\text { Non-EU }\end{array}$ & 480 \\
\hline Netherlands & 450 & $\begin{array}{c}\text { Total } \\
\text { Europe-19 }\end{array}$ & 19850 \\
\hline
\end{tabular}

Figure 1. SME Enterprises Europe - 19

* Source: Estimated by EIM Small Business Research and Consultancy; adapted from Eurostat/DG Enterprise: Enterprises in Europe, Sixth Report. Also based on European Economy, Supplement A, June 1999, and OECD: Economic Outlook, No.65, June 1999. 


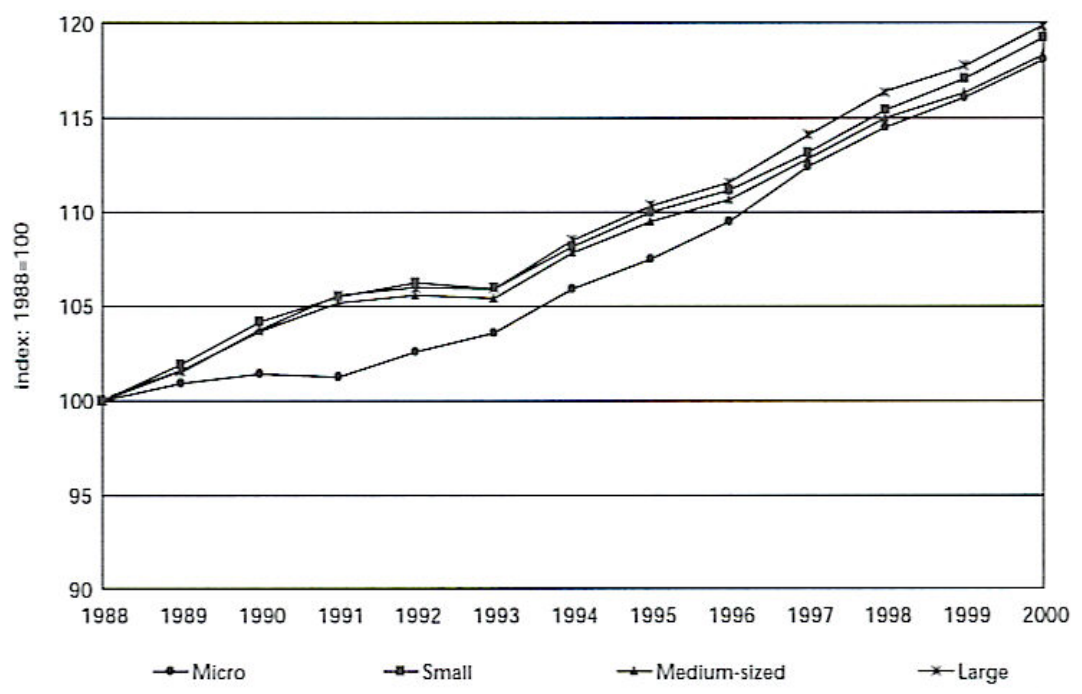

Figure 2. Development of the number of Enterprises, Europe- 19, 1988-2000

However, with these facts known, the traditional strategic management literature is primarily designed with an debatably singularly focused towards large corporations, replete with systems, programs, diagrams, matrices, and plans fully descriptive and mutually supportive of such strategic approaches as joint-ventures, diversification, outsourcing, and strategic alliances for solving different organizational problems.

SMEs face substantial difficulties and challenges when attempting to modify strategies which are primarily designed for large corporation. Furthermore, SMEs are challenged with limited critical mass, strategic budget limitations, misalignment of managerial capabilities, and budget constraints affecting managerial capacity.

Based on the previously discussed limiting factors, achieving optimal strategic success for SMEs utilizing strategies which are formulated for large corporations is unlikely because the SME culture will suffer adverse effects from an inappropriate method of strategy and the firm's financial structure will experience an incongruence of costs to strategic benefit, the results of which often cause the firm to revert to a previously tried, managerial comfortable, ad-hoc mode of incremental planning in frustration.

Despite claims from some critics that formalized strategic planning is difficult to scale with efficacy for smaller firms (Mintzberg, 1990); we argue that the methodologies of the Ansoffian Strategic Management systems can be effective and efficiently scaled, providing optimal strategic results for SMEs.

Specifically, our central argument is as follows: we will examine H. Igor Ansoff Strategic Management systems with the objective of determining the effective scalability and continuity of each system for the requisite strategic planning, formulation, and implementation methods necessary to enable SMEs to successfully compete, given the conditions of moderate to high environmental turbulence. 


\section{Definition of Small and Medium Sized Enterprises}

The determination of the dimensions which constitute and delineates an SME depends on who's doing the defining. Canada, United States, United Kingdom, and the European Union all have systems for identifying and categorizing SMEs with each country recognizing the uniqueness that SMEs have relative to large firms.

One commonly utilized denominator used in varying degree is the number of employees as a determinant of firm size classification. Canada classifies a small business as one that has fewer than 100 employees and a medium business with fewer than 500 employees. The U. S. has chosen to set its size standards for the medium sized SMEs based on individual North American Industry Classification System (NAICS) industry codes, with 500 employees as a limit for manufacturing SMEs, and 100 employees for the wholesale industries SMEs. Additionally, SME size standards are based on both annual revenue and NAICS industry codes, ranging from $\$ 0.75 \mathrm{~m}$ as exampled in sub-sector 111 , crop production; to $\$ 31.5 \mathrm{~m}$ as exampled in sub-sector 622 , hospitals.

According to the European Commission in order to qualify as an EU medium-sized SME a business must have a headcount of fewer than 250, an annual turnover not to exceed a maximum $€ 40$ million, or an annual balance sheet total not to exceed a maximum of $€ 27$ million. EU small-sized businesses are those with a headcount of $10-49$, and EU businesses with $0-9$ employees are classified as micro companies (Loecher, 2000).

The United Kingdom, according to sections 382 and 465 of the Companies Act 2006, defines SMEs by using the numbers of employees, annual gross revenue, and balance sheet total as dimensional qualifiers for SME classification.

Small businesses are classified as:

$>$ having less than $£ 5.6$ million turnover

$>\quad$ a balance sheet total of not more than $£ 2.8$ million

$>$ not more than 50 employees

Medium sized businesses are:

those with less than $£ 22.8$ million turnover

$>$ not more than $£ 11.4$ as a balance sheet total

$>$ and not more than 250 employees.

The Department of Trade and Industry in the United Kingdom and governments in the EU, use the following statistical definitions to classify business size:

$>$ micro firms: $0-9$ employees

$>$ small firms: $0-49$ employees (includes micro)

$>$ medium firms: 50 - 249 employees 


\section{large firms: 250 and above}

Figure 3 is a depiction of global geographic areas and those dimensions which are used to determine and define SMEs. It is evident from this delineation, that with the exception of numbers of employees, a considerable disparity exists on the remaining defining dimensions.

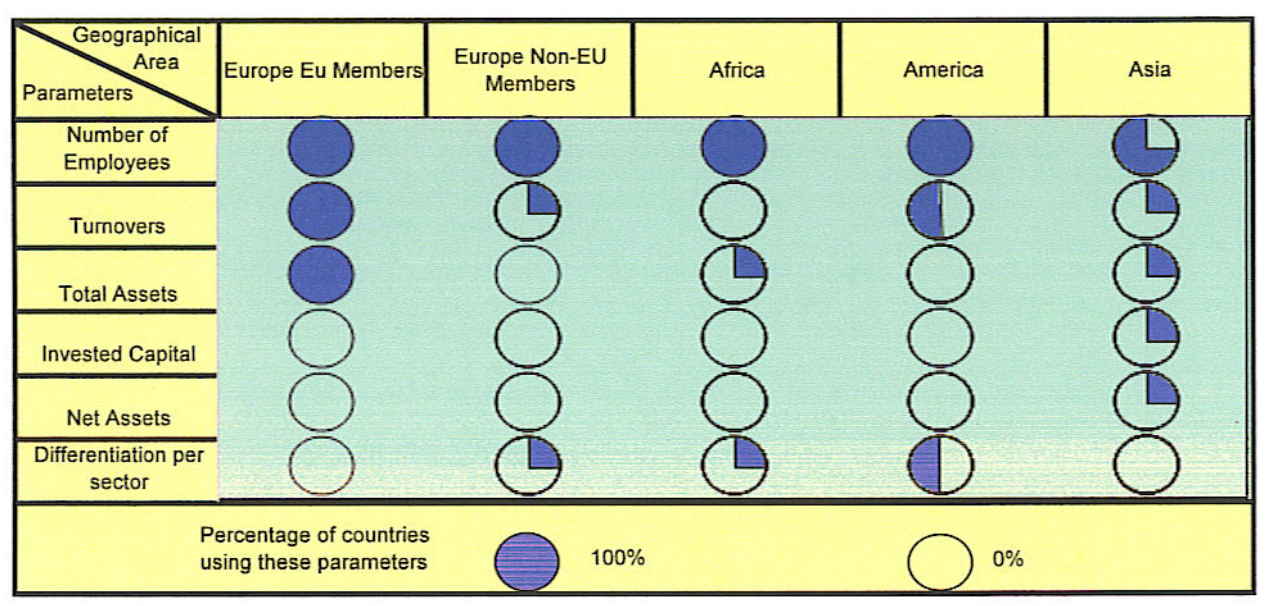

Figure 3. Defining Factors of SMEs

As previously discussed, a disparity exists between the defining dimensions of an SME. Therefore, for specificity and continuity; this review will adapt those dimensions for SMEs as defined by sections 382 and 465 of the United Kingdom Companies Act 2006.

\section{Typology of Environmental Turbulence}

Turbulence, although descriptive of an industry as a whole, does not adequately describe the shifts within certain industries. For example, these effects are clearly supported by the concept of 'disruptive technologies' within industries (Christensen, 1997). Disruptive technologies are best described as those in which the new technological innovation, product, or service, displace or annuls the existing leading technology or process. This phenomenon is represented in two such forms as, convergence of industry and radiation of technology. 'Convergence of industry' (Figure 4) is intrinsically related to the convergence of companies due to technological advancements. The result of this convergence and its related effect on environmental turbulence is manifest on the once distinctly identifiable industry boundaries which now are becoming blurred causing the traditional industry structures to undergo subsequent change thus resulting in company mergers or acquisitions (Cunningham and Tuner, 2002).

Industries, previously focused on globalization, are now decentralized global business networks collecting readily obtainable dichotomous information of both valuable strategic data and information overload from multiple peripheral sources combining to form strategic decisions. 


\section{Macrothink

An example may prove instructive at this point. The cellular communication industry is at the forefront of industry convergence as highlighted with several at one time stand alone industries converging into a single technological unit.

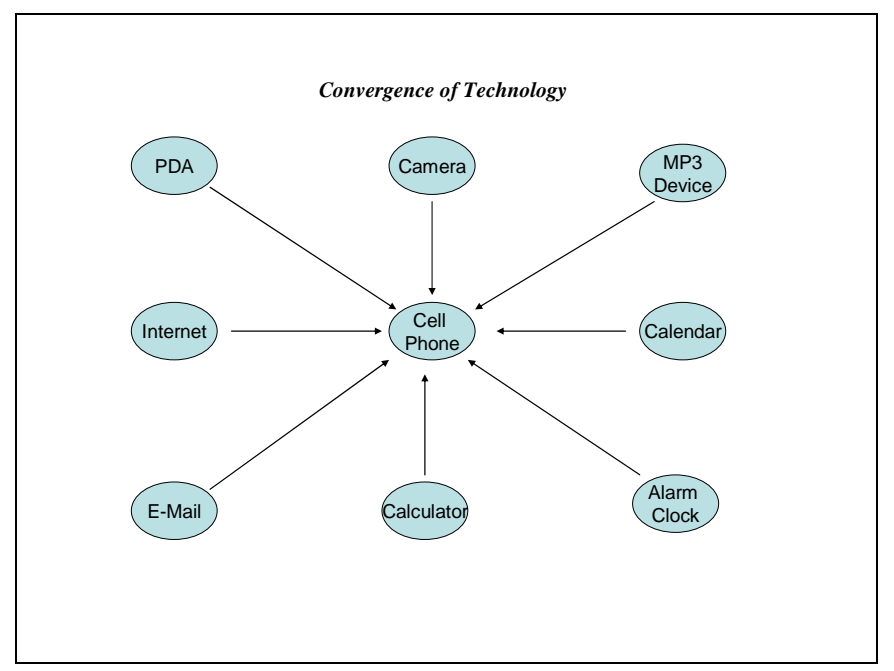

Figure 4. Convergence of Industry

Furthermore, the effect of 'radiation of technology' has developed as a result of technological advancements as depicted in Figure 5. This outcome occurs as a result of a developed technology becoming functionally applicable in originally unrelated industries. An example is the Liquid Crystal Display (LCD), which are used in devices ranging from telephones, to in-dash navigation, as well as computers, to in-home entertainment. Radiance of Technology is exemplified using the ubiquitous memory chip and its related uses in other industries.

The causal affects of both 'convergence of technology' and 'radiance of technology', can have positive as well as negative effects on an existing industry, adding to the discontinuity and unpredictability of the environment in which SMEs compete. 


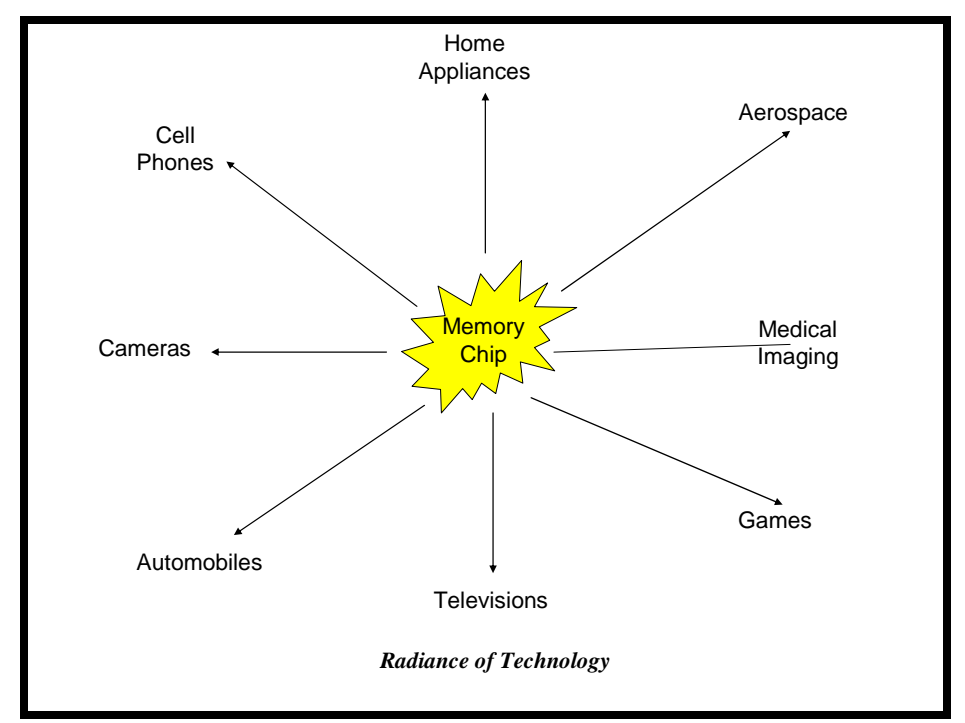

Figure 5. Radiance of Technology

Within any industry, the shifts of turbulence can be caused by four defining factors which move concurrently; (1) The strategic budget level; (2) Unpredictability of change; (3) Novelty of Change; (4) and Frequency of Change. The turbulence level within an industry can vary from; steady turbulence, in which the environment remains in a constant, to; shift in turbulence, which is a rapid departure from one level to another; and finally, drift in turbulence, in which the transition of turbulence from one level to another is gradual.

Ansoff categorized the environment in which SMEs compete into five distinct and definable turbulence levels (Fig. 6) beginning with Level 1, defined as "stable"; within this level the environment has no change and tomorrow will be similar to the present, hence, planning at Level 1 is extrapolative. Level 2 is "expanding"; change is slow and incremental, visible, and predictable. Planning at level 2 is also extrapolative. Level 3 is "changing"; although change is fast, it is still incremental and fully visible. The first three levels of environmental turbulence are sub-classified by Ansoff as "history driven" in that the future is a logical extension of the historical past and present (Ansoff, McDonnell, 1993).

Levels $4 \& 5$ are defined as "discontinuous \& surpriseful” by Ansoff; the future is very different from the historical past and past successes do not guarantee future success. Level 4, a major departure from the extrapolative environment, is defined as "discontinuous". In order to be successful a firm must abandon its historical attachment to particular customers, technologies, and/or products that it was accustomed to in Level 3 and formulate its strategy with a new set of rules. The challenges that face a firm in Level 4 include limited visibility, partial predictability, rapid change and inability of the firm to react to the new change within the time required.

Ansoff's Level 5 is described as "surpriseful"; change at this level occurs without notice, without visibility, unpredictable, and extremely rapid. In order for firms to become successful at this level they must be open and flexible to create products and services with advanced innovative technological ideas. SMEs who compete globally most likely align 
within the description of turbulence Level 5.

An extension of the definition of Levels 3 -5 environment was provided by (Ansoff et. al.., 2004) to include "the pace of change, planned and unplanned product obsolescence coupled with the discontinuous rate of change." This increased intensity changes the existing paradigm of firms focusing solely on industry competitors, and creates a new paradigm which includes threats from unrelated industries".

\begin{tabular}{|c|c|c|c|c|c|c|}
\hline \multirow{7}{*}{ 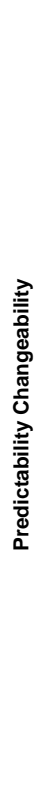 } & $\begin{array}{c}\text { Environmental } \\
\text { turbulence }\end{array}$ & Repetitive & Expanding & Changing & Discontinuous & Surprising \\
\hline & Rate of Change & * & * & $\begin{array}{c}\text { Planned } \\
\text { Obsolescence }\end{array}$ & $\begin{array}{c}\text { Unplanned } \\
\text { Obsolescence }\end{array}$ & $\begin{array}{l}\text { Discontinuous } \\
\text { Rate of Change }\end{array}$ \\
\hline & Complexity & $\begin{array}{l}\text { National } \\
\text { Economic }\end{array}$ & * & $\begin{array}{c}\text { Regional } \\
\text { Technological }\end{array}$ & * & $\begin{array}{c}\text { Global } \\
\text { Socio-Political }\end{array}$ \\
\hline & Familiarity of events & Familiar & Extrapolable & & $\begin{array}{l}\text { Discontinuous } \\
\text { Familiar }\end{array}$ & $\begin{array}{c}\text { Discontinuous } \\
\text { Novel }\end{array}$ \\
\hline & Rapidity of Change & $\begin{array}{c}\text { Slower } \\
\text { than } \\
\text { response }\end{array}$ & & $\begin{array}{c}\text { Comparable to } \\
\text { response }\end{array}$ & & $\begin{array}{l}\text { Faster than } \\
\text { response }\end{array}$ \\
\hline & Visibility of future & Recurring & Forecastable & Predictable & $\begin{array}{c}\text { Partially } \\
\text { Predictable }\end{array}$ & $\begin{array}{c}\text { Unpredictable } \\
\text { surprises }\end{array}$ \\
\hline & Turbulence Level & 1 & 2 & 3 & 4 & 5 \\
\hline
\end{tabular}

Figure 6. Level $4 \& 5$ environments are unstable, unpredictable, rapidly changing,

Discontinuous, novel, and surprising

\section{Dimensions of Ansoff's Strategic Management Systems}

There is strong empirical support linking a positive causal relationship between formalized strategic planning and achieving optimal financial success of a business organization (Ansoff, Brandenburg, and Radosevich. 1971; Burt, 1978: Herald, 1972; Karger and Malik, 1975: Wood and Laforge, 1979). Camillus (1982) supports Ansoff when he stated that the single most important common thread that runs through all synoptic formal approaches is the reliance on an analytical framework that is perceived to be logical and comprehensive'. Hart and Banury (1994) support this earlier work in their research on the strategy-making process and state, the simultaneous use of multiple processes of strategic making facilitates superior performance within particular organizations and environmental contexts.'

Ansoff's Strategic Management Systems are formalized strategic planning systems representing the Planning School view of strategic management. Brews and Hunt (1999) conducted a study that further validate Ansoff and formalized planning as the driving force behind the strategic process, 'this study concludes environment does not moderate the type of planning firms pursue, external firm performance and internal planning performance are 
clearly associated with formal, specific planning, regardless of environment'.

The Planning School posits strategic formulation as a formal process in which a thorough set of procedures are followed and from which, derives a situational analysis requisite to formulate the appropriate strategy. Critics have argued that those firms who follow the Planning School can become too static and that there is a risk of managerial 'groupthink' (Quinn, 1978, 1980; Mintzberg, 1990). Additionally, concerns of environmental predictions are difficult and that it is driven from the top-down allowing little or no subordinate input into the strategic decision making.

This study discusses those systems which are conceptually scalable, add furthermore dynamism to the functionality of SMEs strategic planning, thus answering the critic's claims of invariability and environmental predictability. A taxonomy of these systems include; Long-Range Planning, Strategic Planning, Strategic Management, Strategic Posture Management, Strategic Issue Management, Weak and Strong Signal Responses, and Strategic Surprise Management.

\section{Environmental Surveillance}

As previously stated, the environment in which SMEs compete has become increasingly turbulent due to the intentional internationalization and exponential advancements in technology as contributory industry drivers. Consequently, it is imperative for SMEs to formulate an effective strategic response to ensure having a clear acuity of the future prospects of the firm achievable in a two step method.

First, it is essential that the SME managers have an 'unobstructed' view of their competitive environment. This 'surveillance' is achieved easily by senior level management by completing a segmentation of the firms Strategic Business Areas (SBA) and by identifying in which business areas the SME currently competes, what possible new SBAs can management envision, and viewing the environment holistically as a field of future needs which any competitor may choose to address.

The SBA segmentation process begins with defining the customer needs served, the technology available to serve the need, the type of customer, geographic location of the need, and finally the distribution system that could be used to serve the customer. It is not unusual for SMEs to identify as many as 30 SBA's to address.

The second step for managers is to then identify the growth potential, profitability, and expected turbulence level for each of the SBA's.

The objective of the Strategic Segmentation is to define for the SME managers the distinct segments of the market that require unique managerial competencies. Each segment will have a different growth, profitability, and environmental turbulence level and as a result, will require its own unique strategy.

\section{Long-range Planning}

Scaling Long-Range planning (LRP) for SMEs is not complex given that LRP has no 
strategic analysis elements and no or limited environmental scanning used when determining the long-range goals and objectives of the SME. Ansoff and McDonald (1990) identify LRP as 'a guide for decentralized incremental strategic adaptation'.

The SME senior management is typically tasked with the responsibility of planning the future $5-10 \mathrm{yr}$ performance of the SME by determining the plausibility of the goals and objectives based on extrapolation of the firms' current and past growth performance. LRP is most effective when it is used within the environmental turbulence level (ETL) 1-3.5, in which the environmental strategic 'surprises' and opportunities are clearly visible with changes occurring incrementally, thus allowing the firm's senior management time to interpret the signs and react to the events.

A graphical representation of the procedural steps for Extrapolative LRP is indicated below (figure 7). First, management determines from past experiential data (sales, budgets, usage, customers). The success in achieving current goals and objectives, utilizing this data and determining if the conditions for application mirror historical conditions, apply extrapolative data to determine feasibility of the SME's future goals. After determining future goals, senior management then extrapolates future revenues to determine budgets, profits, and considers future programs for the firm (market expansion, new product line). Consequently, based on an extrapolative exercise, the goals and objectives of the SME are formulated and implemented by the various units of the firm.

Extrapolative Long-Range Planning provides management with a control measure which evaluates the progress in achieving the firm's stated goals and objectives; this information is evaluated to determine if the LRP goals are 'on target' or if goal revisions are required.

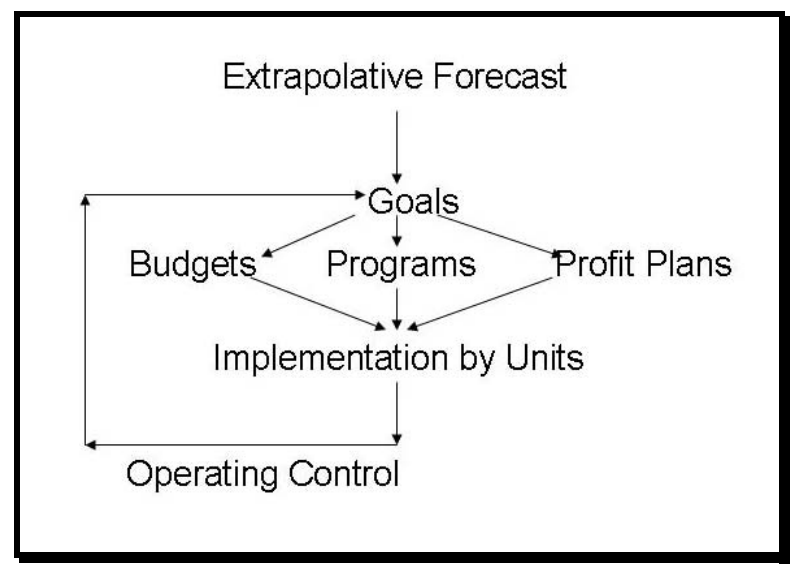

Figure 7. Extrapolative Long-Range Planning

\section{Strategic Planning}

Transitioning from Extrapolative Long Term Planning to Strategic Planning occurs when environmental conditions exist that are rapidly changing and discontinuous in nature. This may occur due to market saturation, new technological developments, governmental regulation, or sudden new entrants into the market. Typically these conditions align with ETL 
$3.5-4.0$.

It is important for SME managers to note that when transitioning from Extrapolative Long-Term Planning to Strategic Planning, the future of the firm is not necessarily expected to be an improvement over the past, therefore planning a success strategy that is based on extrapolation of historical success is not guaranteed.

Strategic Planning is a method that is easily scalable for SME management and can be very effective in spite limited managerial capacity and financial resources. The first step in the method requires an analysis by senior management of the firm's prospects which identifies the firm's trends, threats, opportunities, and 'breakthrough' events which may affect historical trends. Breakthrough events are those singular events in which the end result produces a long-term competitive advantage as well as extraordinary performance results (Ansoff, McDonnell, 1990).

The second step of Strategic Planning is for management to perform a 'competitive analysis', this analysis simply defines an 'improved performance position' of the firm if it is successful in enhancing the competitive strategies of the firms SBAs. This also requires a managerial assessment of the firm's capabilities' and an assessment of the components of such capabilities as supportive agents. Managers may note that even though they may pursue optimal strategies with each SBA, some may perform at higher levels and have greater potential than will others, and still others, it may be determined, may never perform.

Quite simply put, management asks itself the question, 'how will our overall firm performance level increase if we are successful in improving the performance of our SBA's?' Following the competitive analysis, management compares the prospects of each SBA and assigns priorities for implementation and allocates future strategic resources.

The process of Strategic Planning is represented in (Figure 8), which commences with senior management balancing the prospects of the firm juxtapose the firm's objectives in order to determine the firm strategy. SME management then identifies those goals which are 'near-term' performance goals and those which are the firms 'strategic goals'.

Goals which are identified as 'near-term' performance are those which are essential in generating the income for the day-to-day operations of the firm and also provide the requisite resources which are adequate for effective intensity of the strategic budget.

As depicted in Figure 8, for strategic implementation, both operational control and strategic control require a separate and different control system. Hence, it is the duty of the SME management to designate managers possessing the necessary managerial capabilities skills set for each system in order to achieve optimal strategic efficacy. 


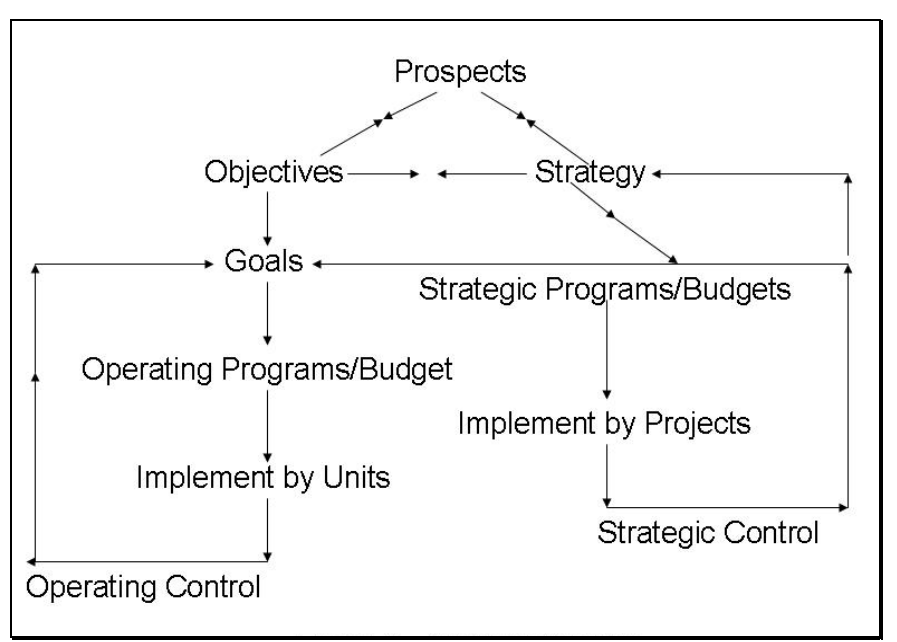

Figure 8. Strategic Planning

\section{Strategic Posture Management}

As we have identified from Strategic Planning, for a SME to compete successfully in a new business area, the firm must have the requisite capabilities and the components of the capabilities must be supportive of each other. One notable difference from traditional strategic management is that strategic posture planning emphasizes an alignment of the firms' external strategy with the necessary internal capabilities to ensure success. This logical progression from strategic planning is best tailored for SMEs competing in high levels of environmental turbulence $4>$.

Following earlier discussions, there are two types of capabilities listed that must support the strategy of the SME, functional and managerial. Functional capabilities are those areas of the firm which create the goods, services, or support ( $\& D$, marketing, production, finance, etc.). It is necessary for the firm to achieve strategic success in that the firms 'functional capabilities' match the strategy. For example, if the firm's strategy is to advance into new product development, it must have the functional capabilities from $R \& D$ and equivalent financial critical mass supporting its strategy in order to achieve this objective.

Managerial capabilities are those capabilities which align the essential personal managerial drive, such as: skills and abilities, knowledge of the (industry and other), cognitive problem solving skills, leadership abilities, communication skills, propensity for risk, creativity, anticipatory, exploring, and entrepreneurial instincts.

In Large Sized Enterprises (LSEs), senior leadership can afford the comfort of capacity to compensate for suboptimal managerial capabilities. This philosophy is akin to 'quantity not quality'. SMEs, however, can ill afford this approach as each manager must have not only the full set of capabilities for his position but also must have the skills to work cross-functionally with other managers, thus making up in ' creative quality' what they lack in 'quantity'.

As Figure 9 illustrates, SMEs strategy must match the Environmental Turbulence Level,

Ssme $=$ Etl, additionally, the firms' functional capabilities and general management 
capabilities must match and support the SMEs strategy as indicated by the symbols

$>\mathrm{Cf}+\mathrm{Cm}=$ OSsme (Optimal Strategic Success).

Thus, optimal strategic success depends on the variants of strategy, the matching and support of the functional capabilities and managerial capabilities, all matching the environmental turbulence level of the firm.

It can therefore be stated that for the SME to achieve optimal strategic success the formula would be:

$$
\mathrm{Etl}=\alpha .+\beta 1 \mathrm{Ssme}+\beta 2 \mathrm{Cf}+\beta 3 \mathrm{Cm}+\varepsilon 1
$$

$>\mathrm{Etl}=$ OSsme (2)

Graphically, a bi-variant representation of each variable (strategy, functional capabilities, and managerial capabilities) would appear similarly to the example given.

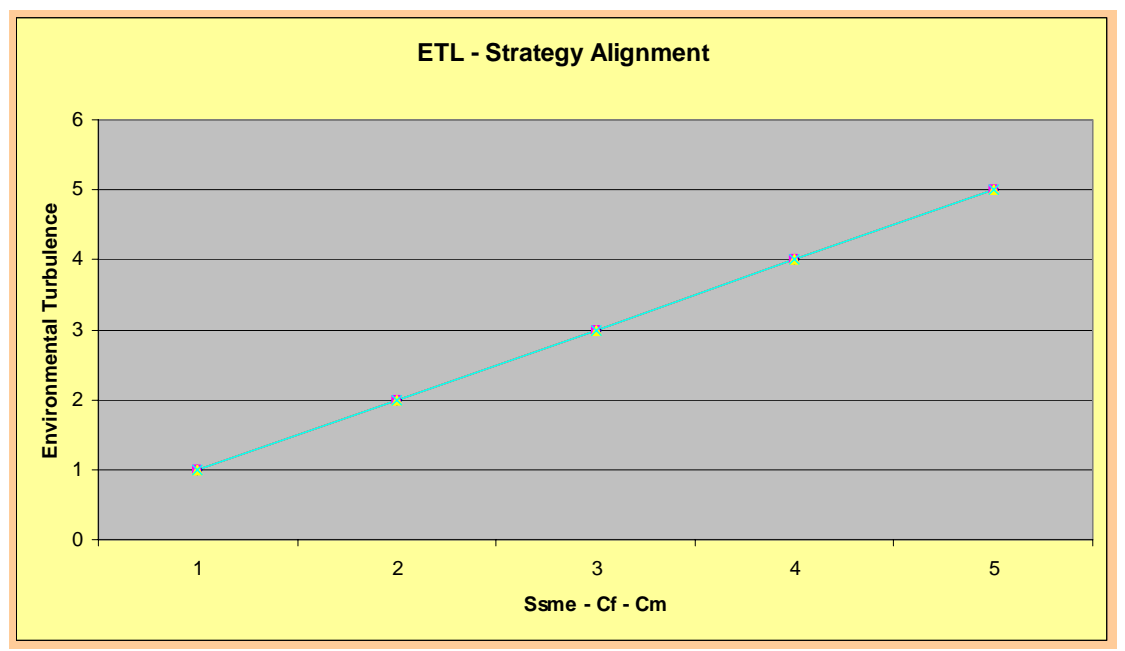

Figure 9. SME-ETL- Strategic Alliance

\section{Strategic Issue Management}

In our previous sections we examined the appropriate strategic uses of both strategic planning and strategic posture planning and adapted methods to accommodate the constraints facing SMEs. As robust as those systems are, they lack the anticipatory dynamism that is requisite to compete in the unpredictable environmental turbulence Levels of 4 and 5.

As aforementioned, the advancements in technology, communications, and globalization have been instrumental driving forces in opening the once domestically dominated markets to international competition. Consequently, SMEs are finding their competitive environment becoming discontinuous, novel, and producing increasingly unpredictable rapid changes. Developing a method for SMEs to effectively address these 'strategic issues' is addressed herewith. 
A 'strategic issue', defined by Ansoff et al., (1991), is a 'forthcoming development, either inside or outside of the organization, which is likely to have an important impact on the ability of the firm to meet its objectives'.

Ansoff's Strategic Issue Management system is a 'real-time system' designed to deal with the rapidly evolving environmental discontinuities. It is a robust, dynamic, response system that is simple to install, easy for SMEs to manage, and does not interfere with the existing structures and systems.

The Strategic Issues Management (SIM) system is deployed using the following processes:

$>$ Senior SME management continuously surveys their potential future external environment (technology, economic, political, social, competition) and intra-firm environment (strengths and weaknesses), from which SME management will evaluate which issue will likely have a significant affect on the firm.

$>$ Management now evaluates each discontinuity on the firm, its effect, level of urgency, and immediacy of response required. Those determined as high impact on the firm are labeled as strategic issues.

$>$ As illustrated in Figure 10, each of the discontinuities are assigned to one of two major responses (Immediate, Delayed) and one of four actionable responses;

o High Impact/High Urgency Issues - Immediate Action is required, SME management assigns a task force 'rapid response unit' to resolve the issue. Unit leader is provided with the necessary resources and authority to circumvent, or usurp any part of the firm to resolve the issue. An example of this state of action is the recent quality safety recalls with toy manufacturer, Mattel Inc.

o High Impact/Moderate Issues - Requires a delayed response - Strategic issue are designated for review at next scheduled planning session.

o High Impact/Low Urgency Issues - Delayed response - Issue is continually monitored and evaluated for change in urgency. If status changes to high urgency, it is immediately assigned a task force leader. If the status reduces it may be placed in the 'Dead file'.

o Discontinuities whose impact are low on the firm and not expected to change are placed in No Action 'Dead file' status.

It is observable from Figure 10, that in order to achieve maximum efficacy and become a robust, effective, strategic tool for SME management use, SIM simply requires the management assignment of an active continuous environmental scanning unit and a system to identify and classify strategic issues.

SIM is an effective, flexible, simple, and conceptually buoyant program when compared juxtapose the annual planning cycle. It does carry one caveat, however; the program must have the time, attention, and commitment of senior SME management to be an effective strategic tool. 


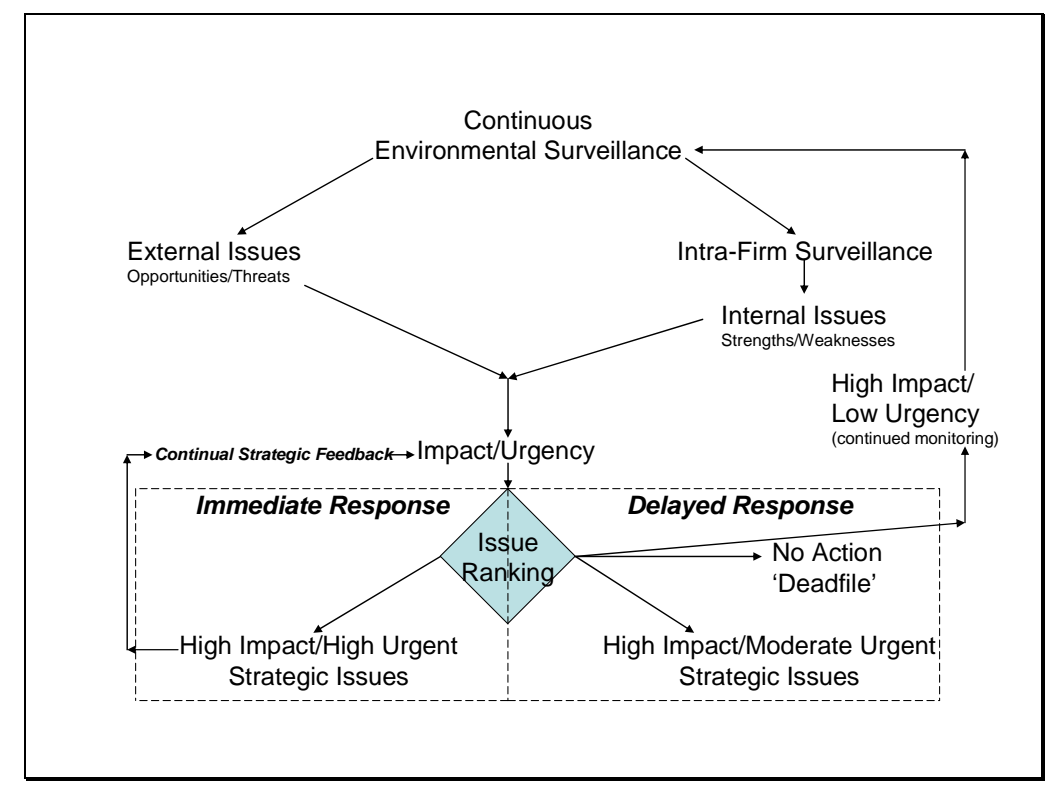

Figure 10. Strategic Issue Management

\section{Weak signals \& strong signals Responses}

The discussion in the previous section on Strategic Issues management, assigning and ranking issues is based on the signal strength and available information at the time of surveillance. Some signals will have more or less information than others. This process alone, albeit dynamic, leaves management in a strategically exposed position when competing in the rapidly changing, discontinuous environmental turbulence levels of 4-5.

As is common at Environmental Turbulence Level (ETL) 4-5, issues develop with more rapidity and novelty than is reaction time available. Managers are challenged to formulate a clear and unambiguous response a task which is all but impossible based on information signals that are 'weak', unspecified, incomplete, and unidentified.

For specificity of definition, Ansoff, Antoniou, \& Lewis (2004) define 'weak signals' as those 'which carry an imprecise early indication about impending impactful events' and 'strong signals' as those 'issues with sufficient visibility and concrete data to permit a firm to develop specific and timely responses'.

For example, it is observable that, in the next few years, Russia will play an ever increasingly important role in the world's energy supply. However, given the important political leadership posturing that is underway in today's Russia, it is unclear to predict with any confidence as to how Russian politics will affect supply of global energy. Firms whose interest may be directly or indirectly affected by Russia's energy position would consider these actions as 'weak signals'. Therefore, it is essential for SMEs to start their response as the signals are still weak as over time the weak signals will become stronger, limiting the response time for the firms to formulate a clear and unequivocal response.

The adaptation process of weak and strong signals response is easily accomplished for SME 
management. Using the issue ranking and identification process from the Strategic Issue Management method, SME management determines which signals are 'weak signals' and which ones are designated 'strong signals'. With the strong signals it is possible for management to select a definitive response to the issue. However, with the weak signal, it is difficult to determine if the signal is a threat or an opportunity, management's position should be one of 'preparatory'.

Ansoff \& Antoniou (2005) have developed a preparatory matrix (Figure 11) which identifies signal strength which evolves over time (ranging from 1 very weak 'sense of turbulence' to 6 'impact will be felt') combined with the appropriate managerial strategy and necessary capabilities to correspond with the issue signal level strength.

\begin{tabular}{|c|c|c|c|c|c|c|}
\hline $\begin{array}{c}\text { Signal } \\
\text { Strength } \\
\text { Response }\end{array}$ & $\begin{array}{c}1 \\
\text { Lenel } \\
\text { Turbulence }\end{array}$ & $\begin{array}{c}2 \\
\text { Source of } \\
\text { Turbulence }\end{array}$ & $\begin{array}{c}3 \\
\text { Discontinuous } \\
\text { Level }\end{array}$ & $\begin{array}{c}4 \\
\text { Response } \\
\text { Identified }\end{array}$ & $\begin{array}{c}5 \\
\text { Outcome } \\
\text { Predicted }\end{array}$ & $\begin{array}{c}6 \\
\text { Impact Felk }\end{array}$ \\
\hline STRATEGIC & $\begin{array}{c}\text { Enhance } \\
\text { Surveillance }\end{array}$ & Diversify Risk & $\begin{array}{c}\text { Create } \\
\text { Response }\end{array}$ & $\begin{array}{c}\text { Launch High } \\
\text { Risk Response }\end{array}$ & $\begin{array}{c}\text { Launch Low } \\
\text { Risk Response }\end{array}$ & $\begin{array}{c}\text { Launch Catch- } \\
\text { up Response }\end{array}$ \\
\hline CAPABILITIES & Audit Flexibility & $\begin{array}{c}\text { Increase } \\
\text { Flexibilty }\end{array}$ & $\begin{array}{c}\text { Acquire Basic } \\
\text { Technology }\end{array}$ & $\begin{array}{l}\text { Build Minimum } \\
\text { Capabilty }\end{array}$ & $\begin{array}{c}\text { Build Full Scale } \\
\text { Capability }\end{array}$ & $\begin{array}{c}\text { Crash Buildup } \\
\text { of Capabilty }\end{array}$ \\
\hline
\end{tabular}

Figure 11. Possible Responses at Signal Strength Levels

Using our previous example of energy in Russia, when information is developing and signals are still formative, SME managements strategic posture is one of enhanced surveillance and positioning the internal capabilities for a 'flexible position' to react based on increasingly developing information. As the signal strength increases (information is now becoming more reliable, accurate, and available) SME management aligns its strategy, and capabilities to respond to the more visible threat/opportunity. Finally, at signal strength Level 6, the full impact of the issue is known by this point if SME management has not used preparatory strategy. It is forced to launch an expensive 'catch-up' response as well as an emergency, expensive 'crash buildup of capacity'. Implementing a catch-up strategy and requisite crash buildup capability is extremely expensive, culturally disruptive, ineffective, and exhausts the firm's resources unnecessarily. SME management should properly instruct those charged with Strategic Issue management with signal identification recognition to prevent unwarranted surpriseful financial losses. Figure 12 depicts the Priority Assignment of issues using Weak Signals SIM. 


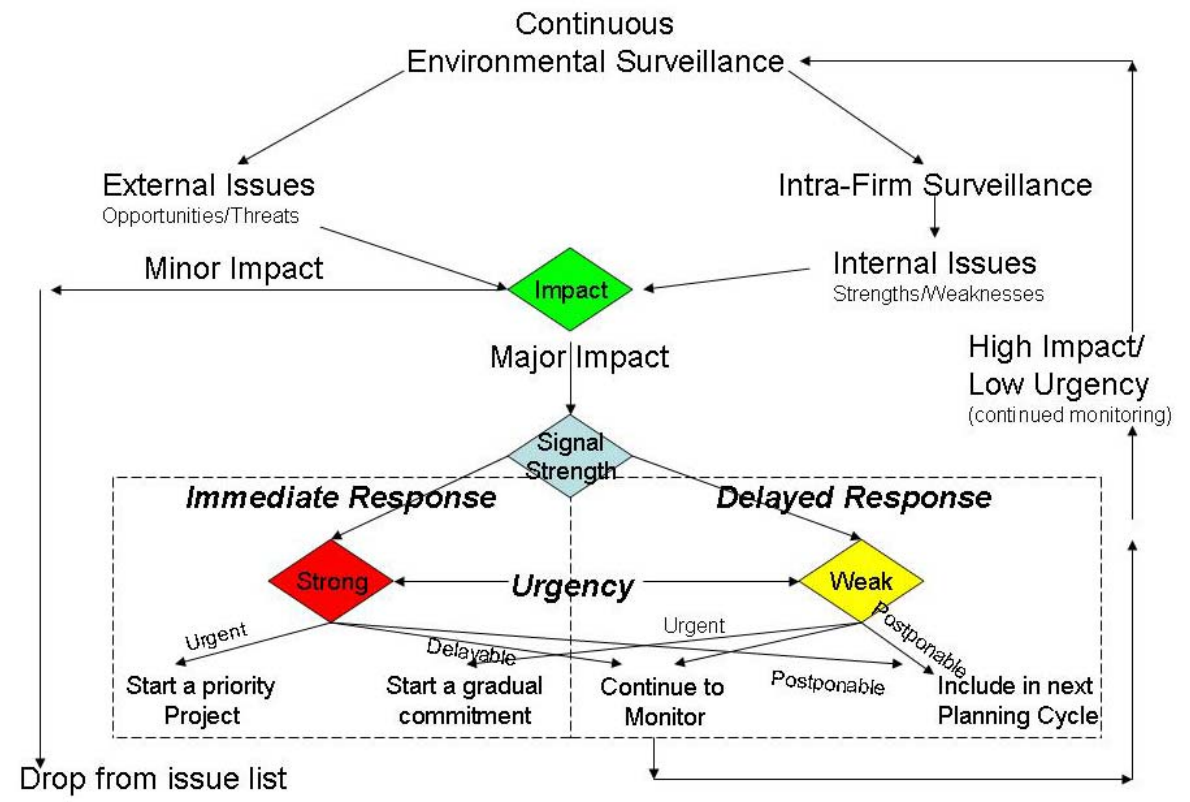

Figure 12. Priority Assignment Using Weak Signal SIM

\section{Strategic Surprise Management}

The former president of the North Atlantic Assembly (the Parliamentary Arm of NATO) and leader of the first Western parliamentary delegation to the Kremlin, Sir Patrick Duffy stated at a recent economic summit conference (2007), 'despite the extensive military intelligence available to NATO, the United States, and to Great Britain, to a man, all were completely surprised by the fall of the Berlin Wall'.

Surprise happens! Simply stated, even with the most sophisticated methods of environmental scanning used, some issues will be missed and become 'Strategic Surprises'. Therefore, management's challenge is not preventing surprise and its subsequent frustrations. It is coping with the effects of those surprises that we are unable to prevent.

Ansoff, Antoniou \& Lewis (2004) defines a 'Strategic Surprise' with four factors:

1. The issue arrives suddenly, unanticipated.

2. It poses novel problems in which the firm has little prior experience.

3. Failure to respond implies either a major financial reversal or loss of a major opportunity.

4. The response is urgent and cannot be handled promptly enough by the existing systems and procedures.

As noted with our previous strategic methods, formulation and implementation was based on a foreknowledge of the issue. However, lack of issue preeminence places management in an untenable position of widespread panic.

When encountering a strategic surprise, the firm will attempt to gather as much information 
on the 'surprise' as possible, requiring immediate filtering, processing, and analyzing in an effort to determine the extent of the issue and to then formulate an appropriate strategic response. This massive influx of information will produce an overload of information creating conditions that are difficult for management to make a clear, cognitive, timely, decision.

H. Simon (1957) referred to this condition as 'bounded rationality' defined as, "rational choice(s) that takes into account the cognitive limitations of both knowledge and cognitive capacity of both individuals and corporations." Although it has been argued by some in academia that bounded rationality exists in any strategic situation, the probability of such and the extent of such condition is remote when events are clearly visible, familiar, predictable, and timing for the strategic decision is unlimited. Simon's 'bounded rationality' position is again supported by recent research conducted by Gavetti and Levinthal (2005) into strategy making in a novel and complex world when they state;

'It is precisely in complex worlds of highly interactive systems that deductive reasoning and rational choice seem least able to pinpoint effective positions. If the choices involved in a strategy are numerous and each affects the pay-offs associated with many others, the computational load created by a deductive process can quickly outstrip the bounded processing power of any management team'.

Decentralized management principles will prove to be ineffective during a 'strategic surprise' and will only add to the discontinuity, as the differing departments will be moving in an uncoordinated 'all directions at the same time' panic in an effort to solve what they perceive to be the most preeminent issue.

It is imperative for those SMEs which expect to compete in environmental turbulence levels close to Level 5 to invest in a Strategic Surprise System and to exercise the system networks under non-crisis situations to improve communication and system effectiveness.

Considering the limited managerial capacities with which SMEs are faced, this system focus is on procedural activities as opposed to a capital investment; however, a review of current technology may warrant an upgrade to ensure system robustness.

For the duration of the Strategic Surprise:

1. An Emergency Communication network is established - This network is charged with filtering the incoming information and expeditiously dissemination the information to the entire firm.

2. Top managers are repartitioned into 3 groups -

a. Devotes attention to firm's morale.

b. Maintains 'business as usual' with minimum disruptions.

c. Charged with resolution of the 'surprise'.

3. A strategic task force network is activated - 


\section{Macrothink}

Journal of Management Research

ISSN 1941-899X

2009, Vol. 1, No. 1: E6

a. Leaders and members have 'special' strategic action powers (not just planning).

b. Establishment of 'cross-functional' communications channels with task force members and top management (Task-force members will consist of SME management).

c. Trained to respond promptly to novel problems.

4. Top management formulates overall strategy -

a. Assigns implementation responsibilities and coordinates the implementation.

b. Task force can formulate and implement strategies within their area of responsibility.

5. SME management may decide to add other networks to address:

a. Surprises in the marketplace.

b. Technological surprises.

c. Political surprises.

Figure 13 depicts the procedural control elements of the Strategic Surprise System. SMEs will find implementation of the Strategic Surprise system achievable only with managers whose mindset and capabilities match environmental turbulence Level 5.

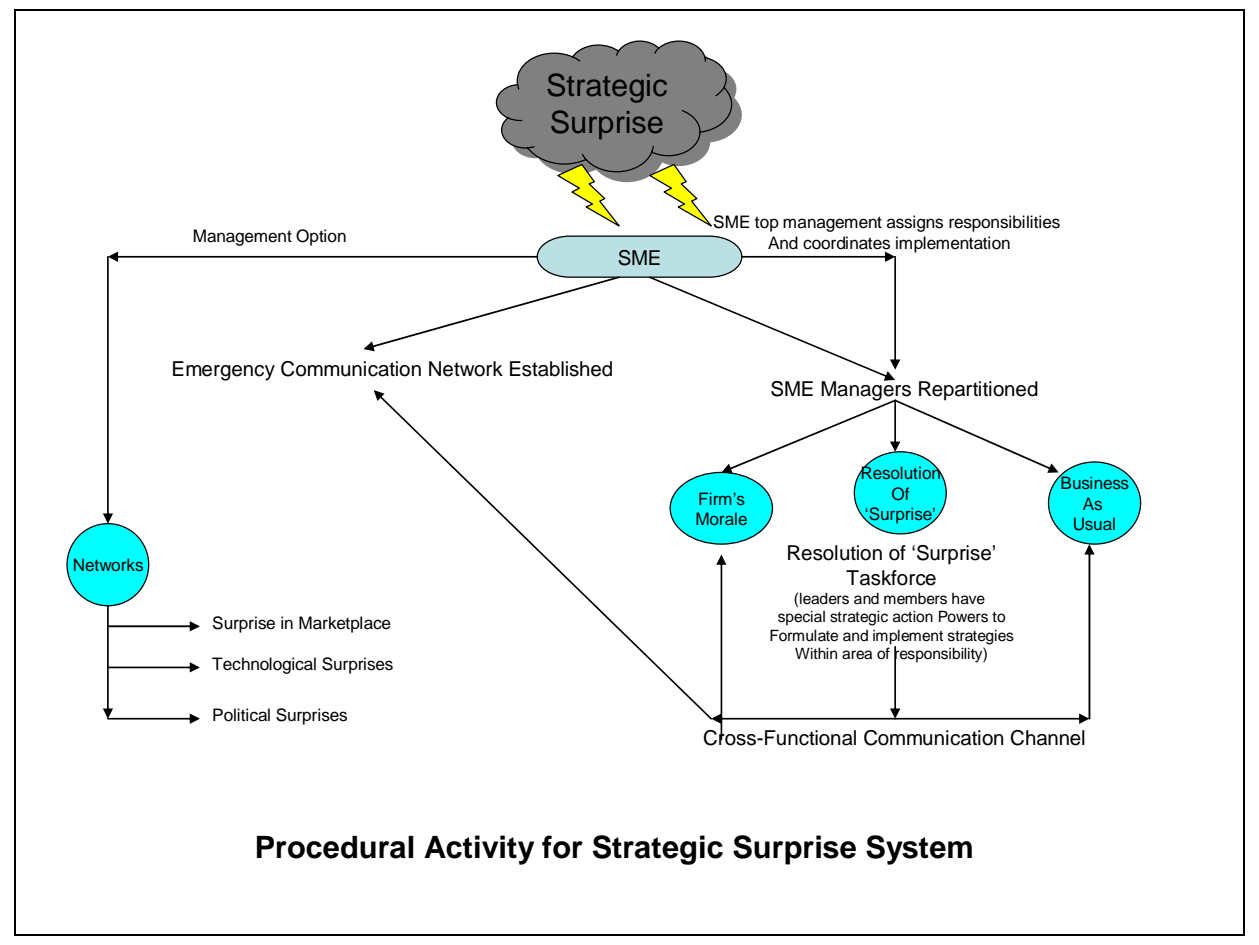

Figure 13. Procedural Activity for the Strategic Surprise System

\section{The Strategic Imperative of Information Coupling}

The global competitive environment is impartial. It is both equally opportunistic to firm size 
as well as equally intolerant of firms lacking efficacy. Unlike LSEs, Small and Medium Sized firms are challenged with a unique set of complications- those of limited capacity and resources. In order to compete on parity, SME's must develop superior skills to account for the disparity in economies of scope, scale, resource limitations, and critical mass.

One viable solution that is within the financial scope of SMEs and will assist in closing this 'size gap,' is the development of a robust information coupling system that integrates all units within the firm on a common level.

A robust system of information coupling provides unison to the firm employees creating a common language and vocabulary (Nahapiet, Ghoshal, 1998; Grant, 1996b). Additionally, information coupling enables SME managers to reduce decision making times as well as reducing internal competition for resources, skills, and funding, and limits external environmental strategic surprises (Grant, 1996a).

It is therefore crucial for SME managers to implant and promote a robust communications exchange network coupling all of the firm's functional units with each other. This coupling of knowledge will provide the SME management teams with vital Knowledge Management $(\mathrm{KM})$ processes, including information discovery, capture, sharing, and application.

Furthermore, the implementation of a robust KM system linking the functional units, systems, structure, and capacity of management, blends and integrates the entire organizations contributions and concerns.

This 'combined action potential' is defined by Ansoff, Declerck, and Hayes (1976) as the organization's capabilities and is essential for SME management in formulating the firm's strategy and when responding to an environmental discontinuity.

Figure 14 depicts an SME with four functional units displayed- as indicated, process (information or product) flows between the functional units, this 'Common Knowledge' (Grant, 1996a) is the accumulation of the firm's experiences in comprehension and organizational activities, as well as those experiences that support the firms vision, mission, and strategies.

Ansoff et al., (1976) suggests that this Integrative Management approach to information coupling must be included to link those activities and interactions between operating and strategic behaviors in order for a firm to have the proper perspective requisite for translation of the firm's strategic plans into strategic reality. 


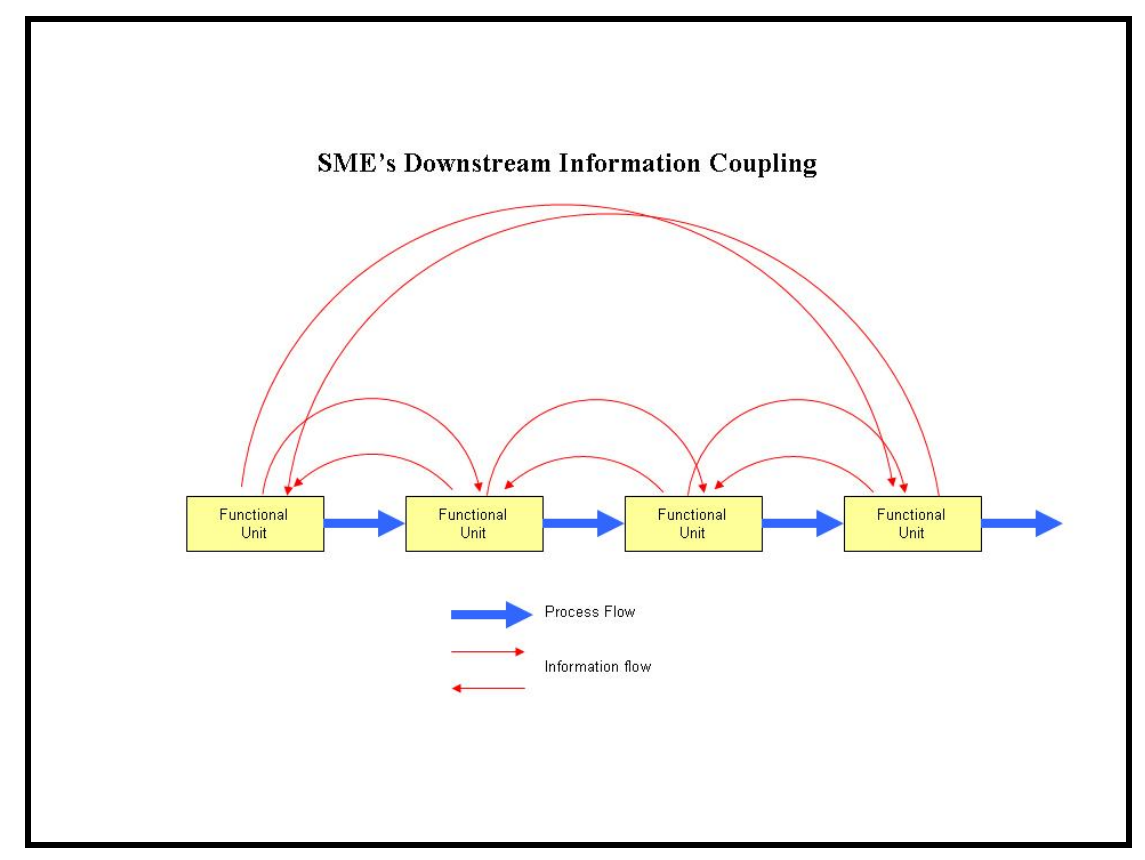

Figure 14. SME Information Coupling

\section{History of the Strategic Success Paradigm}

During the 1960's and 1970's, advancements into the study of strategic management ensued with identification of several key success variables that support Ansoff's Strategic Success Paradigm structural components.

The foundation of the paradigm components begins with taxonomy of observable environments which are discrete and different from one another. This was first identified in a paper published in a volume of the Human Relations by F.E. Emery and E.L. Trist in 1965. This early observation and typography of environmental discontinuities provide support for Ansoff's first rule of the strategic success paradigm; "The aggressiveness of the firm's strategic behavior must match the turbulence of its environment."

Management's capabilities and their significance in formulating and implementing strategy was discussed by Alfred D. Chandler in a book titled Strategy and Structure, (MIT Press, 1972) in which he presents finding identifying commonalities in strategic adaptation to environmental discontinuities and the need for management to adapt strategy which will be most effective with each identified environmental discontinuity.

Research conducted by Lyles \& Salk (1996) on the role of firm's internal capabilities and knowledge found that 'the development of capabilities and competencies in firms has been shown to have a positive effect upon various facets of performance'. Another study confirming the concept of corporate strategy and the significance of managerial support was presented by Andrews in 1971 as "the pattern of decisions that determined a company's goal, produced the principle policies for achieving these goals, and defined the range of businesses the company was to pursue". 
Chandler's, Lyles \& Salk, and Andrews' research provide validation for Ansoff's second rule in the paradigm; "The responsiveness of the firm's capabilities must match the aggressiveness of its strategy."

Ansoff's identification of the success variables was confirmed by empirical research conducted by Leonidou, Katsikeas, \& Samiee (2002) supporting both the existence and the importance for firms to address the variables in the formulation of the firm's strategies as a determinant of performance and success factors.

Miller and Freisen (1984) recognize that the nexus of the variables constitute a complex range of independent variables. It is these variables that must remain coupled in a state of dynamic equilibrium, regardless of environmental turbulence. Miller and Freisen's research validates Ansoff's third component of the strategic success paradigm: "The components of the firm's capabilities must be supportive of one another."

Using the foundational research developed from Chandler, Andrews, and Emery, et al., Ansoff identifies the three requisite variables for a firm's optimal financial success and from these variables, formed the conventions for the Strategic Success Paradigm.

\section{Variables Forming the Strategic Success Paradigm}

1. The aggressiveness of the firm's strategic behavior must match the turbulence of its environment.

2. The responsiveness of the firm's capabilities must match the aggressiveness of its strategy.

3. The components of the firm's capabilities must be supportive of one another.

As previously mentioned, the research conducted by Emery and Trist into discrete and different environments led Ansoff to develop a typology of 5 distinct identifiable levels of environmental turbulence. These five distinct environmental turbulence "levels" are based on the complexity of the environment, the speed of change relative to the possible speed of response, the visibility of the future and the predictability of the future.

Zahra et al. (1997) supports Ansoff's typology when similarly describing the dimensions of environmental turbulence by including the following in their description of the environment; heterogeneity (diversity of markets), dynamism (rate and unpredictability of change) and hostility (unfavorable business climate, high level of competitive intensity and uncertainty) Zahra \& Bogner (1999); and Zahra et al., (1997).

\section{The Paradigmic Summary of Sme Scaleability}

The basic strategic management paradigms of Porter, Mintzberg, Ansoff, and Drucker focus their solutions for a firm's achievement of strategic success with an ardent singular consideration, solely towards LSEs.

What is presented in this paper is a plausible paradigm shift illuminating how SME managers can easily adapt H. Igor Ansoff's strategic management methods for effective use to translate strategic plans into a viable strategic solution. 
The major characteristics of the Paradigmic shift are the following:

1. Strategic evolution - SME managers must have a mindset change replacing the more traditional method based on the extrapolative method of strategic formulation. Managers must remember that the future is not guaranteed and is not necessarily an improvement over the past successes.

2. Capabilities evolution - SMEs must continually evolve their organizational capabilities to account for the increased demands from the environment. This includes but is not limited to: evolution of the organizations culture, management, structure, systems, and power structure (Ansoff, 1987).

3. Information coupling evolution - As alluded to previously, due to size, SMEs are resource constrained. Hence, the implementation and execution of a robust Knowledge Management System that specifically cross-couples the functional units is imperative. Information coupling supports transfer of knowledge and vital information, providing SME management with a tool to close the size advantage disparity gap.

4. Managerial evolution - The managerial mindset of SME managers must be creative, risk-taking, visionary, and entrepreneurial nature in order to match the turbulent environmental discontinuities facing today's firms. Senior management must have the goal of only aligning its management team with those individuals whose goals, mentality, leadership, problem solving skills, and knowledge, create the best 'managerial competencies fit' to match the firm's environmental conditions.

\section{References}

Andrews, K. (1971). The concept of Corporate Strategy, Irwin, Burr Ridge, IL.

Ansoff, H. I. (1987). The Emerging Paradigm of Strategic Behavior. Strategic Management Journal, Vol. 8, 501-515.

Ansoff, H. I., Antoniou, P. \& Lewis, A.O. (2004). 'Strategic Management: Introduction to the Ansoffian Approach'. Xanedu Press: Michigan.

Ansoff, H. I. \& Antoniou, P. (2005). The Secrets of Strategic Management: The Ansoffian Approach. Booksurge, LLC.

Ansoff, H. I., Brandenburg, R. G., \& Radosevich, R. (1971). Acquisition Behavior of U.S. manufacturing firms, 1946-1965, Vanderbilt Press, Nashville.

Ansoff, H. I., Declerck, R. P. \& Hayes, R. L. (1976). From Strategic Planning to Strategic Management, John Wiley, New York.

Ansoff, H. I., McDonnell, E. (1990). Implanting Strategic Management. New York: Prentice Hall.

Berger, A. N., \& Udell, G.F. (1998). The Economics of Small Business Finance: The role of private equity and debt markets in the financial growth cycle. Journal of Banking and Finance, 22.6-8, pp. 873-897. 
Brews, P.J. \& Hunt, M.R. (1999). "Learning to plan and planning to learn: Resolving the planning school/learning school debate” Strategic Management Journal, Vol.20: 10.

Burt, D. (1978). Planning and performance in Australian retailing, Long Range Planning, 11, pp. 62-68.

Camillus, L.C. (1987). Contrasting Planning Systems in high, medium and low Performance Companies. Journal of Management Studies 24 (4), 363-385.

Chandler, A.D. (1972). Strategy and Structure, MIT Press, Cambridge, MA.

Christensen, C. M. (1997). The Innovator’s Dilemma, Harvard Business School Press.

Cunningham, S and Turner, G. (eds). (2002). The Media and Communications in Australia. Sydney: Allen \& Uwin.

D’Aveni, R. (1994). Hyper Competition, Managing the Dynamics of Strategic Maneuvering. New York: Free Press.

Day, G. S., \& Reibstein, D. J. (1997). Wharton on dynamic competitive strategy. New York: John Wiley \& Sons.

Emery, E. and Trist, E. L. (1965). The causal texture of organizational environment. Human Relations, Vol. 10.

Eisenhardt, K., \& Brown, S. (1998). Competing on the Edge: Strategy as Structured Chaos. Cambridge: Harvard Business School Press.

Galbraith, J. (2002). Designing Organizations, An Executive Guide to Strategy, Structure, and Process. San Francisco: Jossey Bass.

Grant, R. M. (1996a). Prospering in dynamically competitive environments: Organizational capability as knowledge integration. Organization Science, 7(4), 375-387.

Grant, R. M. (1996b). Toward a knowledge-based theory of the firm. Strategic Management Journal, 17, 109-122.

Hart, S., \& Banbury, C. (1994). How Strategy-Making Processes can make a Difference. Strategic Management Journal, 15, 4, 251-269.

Herold, D. (1972). Long range Planning and organizational performance: a cross validation study. Academy of Management Journal, 15, pp.91-102.

Karger, D., \& Malik, Z. (1975). Long Range Planning and organizational Performance. Long Range Planning, 8, pp. 60-64.

Loecher, U. (2000). Small and medium sized Enterprises: Delimitations and the European definition in the area of Industrial Business. European Business Review, Vol. 12, Iss. 5. Pp.261.

Leoidou, L.C., Katsikeas, C.S., \& Samiee, S. (2002). Marketing strategy determinants of export performance: A metaanalysis. Journal of Business Research, 55 (1), 51-67. 


\section{Macrothink}

Journal of Management Research

ISSN 1941-899X

2009, Vol. 1, No. 1: E6

Lyles, M.A. and Salk, J.E. (1996). 'Knowledge acquisition from foreign parents in international joint ventures: an empirical examination in the Hungarian context', Journal of International Business Studies 27(5): 877-903.

Miller, D.C., and Freisen, P. H. (1984). Organizations: A Quantum View, Englewood Cliffs, NJ: Prentice Hall.

Mintzberg, H. (1990). The Design School: Reconsidering the Basic Premises of Strategic Management. Strategic Management Journal, Vol. 11, 171-195.

Nahapiet, J., and Ghoshal, S. (1998). Social capital, intellectual capital, and the organizational advantage. Academy of Management Review, 23(2), 242-266.

Normann, R. (2001). Reframing Business: When the Map Changes the landscape. Chichester: John Wiley and Sons.

Pichler, J.H., Pleitner, H.J., Schmidt, K.H. (1996). Die Fuhrung von Klein, und Mittellenternerhmen, Vol. 2, Bern, Stuttgart, Vienna, pp. 11-18.

Quinn, J. B. (1978). “Strategic Change: Logical incrementalism”, Sloan Management Review, Fall, 1978, pp. 7-21.

Quinn, J. B. (1980). Strategies for Change: Logical Incrementalism. Englewood Cliffs, NJ: Irwin.

Scholars for Business Achievement. (2007). Economic Summit 2007. Retrieved from; http://www.sba.bz/new_sba_website_002.htm.

Simon, H. A. (1957). The Models of Man: Social and Rational, John Wiley and Sons, New York, NY.

SMEs in Focus: The Observatory of European SMEs, 2002. (2002). European Communities, Belgium, ISBN 92-894-3589-5.

Wood, D. R., \& LaForge, R. L. (1981). Toward the development of a planning scale: an example from the Banking Industry. Strategic Management Journal, 2, pp. 209-216.

Zahra, S.A. \& Bogner, W. C. (1999). Technology strategy and software new ventures' performance: Exploring the moderating effect of the competitive environment. Journal of Business Venturing, /5(2), 135-173.

Zahra, S.A., Newbaum, D.O., \& Huse, M. (1997). The effect of the environment on export performance among telecommunications new ventures. Entrepreneurship Theory and Practice, 22 (1), 25-46. 